\title{
Effects of nitridation and annealing on interface properties of thermally oxidized $\mathrm{SiO}_{2} / \mathrm{SiC}$ metal-oxide-semiconductor system
}

\author{
P. T. Lai, ${ }^{\text {a) }}$ Supratic Chakraborty, C. L. Chan, and Y. C. Cheng \\ Department of Electrical and Electronic Engineering, the University of Hong Kong, Pokfulam Road, \\ Hong Kong
}

(Received 24 January 2000; accepted for publication 21 April 2000)

\begin{abstract}
The effects of $\mathrm{N}_{2} \mathrm{O}$ nitridation and subsequent annealing in different conditions on thermally oxidized $n$-type $6 \mathrm{H}$-silicon carbide $(\mathrm{SiC})$ metal-oxide-semiconductor (MOS) interface properties were investigated. Influence of high-field stress on the MOS system was also studied. The nitrided device annealed in dry or wet $\mathrm{O}_{2}$ is found to have lower interface-state density compared to the device annealed in $\mathrm{N}_{2}$ because the reoxidation can reduce nitridation-induced interface damage. Furthermore, significantly less shift of flatband voltage during high-field stress for all nitrided devices indicates much better oxide reliability by replacing strained $\mathrm{Si}-\mathrm{O}$ bonds with stronger $\mathrm{Si}-\mathrm{N}$ bonds during nitridation. This is further supported by the fact that annealing of the nitrided device in dry or wet oxygen slightly reduces the robustness of the oxide. In summary, the $\mathrm{O}_{2}$-annealing conditions have to be optimized to deliver a proper tradoff between interface quality and reliability. (C) 2000 American Institute of Physics. [S0003-6951(00)01025-1]
\end{abstract}

In recent years, much attention has been paid to exploit SiC's performance in high-power, high-temperature, and high-frequency electronics because of its superior properties such as wide band gap, high breakdown field, saturation drift velocity, and thermal conductivity. One of the most important advantages of $\mathrm{SiC}$ over other wide-band gap semiconductors is that $\mathrm{SiC}$ can be thermally oxidized to form an insulator $\mathrm{SiO}_{2}$. However, oxides grown on $\mathrm{SiC}$ with high interface-state density and a large amount of fixed charges, especially for the $\mathrm{SiO}_{2} / p-\mathrm{SiC}$ structure, have been reported. ${ }^{1,2}$ Nitridation of oxides on $\mathrm{SiC}$ significantly affects $p$-type oxides, while the effects on $n$-type oxides are marginal. ${ }^{3}$ In this work, the role of annealing of $\mathrm{N}_{2} \mathrm{O}$-nitrided oxides in different ambients is investigated. Results on the effects of high-field stress on the oxides are also presented.

$\mathrm{Si}$-faced $n$-type $6 \mathrm{H}-\mathrm{SiC}$ wafers, manufactured by CREE Research, were used in this experiment. The $\mathrm{SiC}$ wafers had a $5 \mu \mathrm{m}$ epitaxial layer grown on heavily doped substrates. The doping level of the epitaxial layer was $4 \times 10^{15} \mathrm{~cm}^{-3}$. The conventional RCA method was employed to clean the wafers. Immediately before oxidation, the wafers were dipped in $1 \% \mathrm{HF}$ for $60 \mathrm{~s}$ and then loaded into an oxidation furnace at $800{ }^{\circ} \mathrm{C}$. After raising to an oxidation temperature of $1100^{\circ} \mathrm{C}$, one sample was oxidized in a wet ambient by bubbling oxygen through de-ionized water at $95^{\circ} \mathrm{C}$ for 150 min. After oxidation, the sample was then annealed in $\mathrm{N}_{2}$ for 30 min (denoted as OX). The oxidation of three other samples was done under the same conditions. They were then nitrided in $\mathrm{N}_{2} \mathrm{O}$ at a flow of $250 \mathrm{ml} / \mathrm{min}$ at $1100^{\circ} \mathrm{C}$ for 90 min and annealed for $30 \mathrm{~min}$ in $\mathrm{N}_{2}$ (denoted as $\mathrm{N} 2 \mathrm{ON}$ ), dry $\mathrm{O}_{2}$ (denoted N2OD) and wet $\mathrm{O}_{2}$ (denoted as N2OW), respectively. Aluminum was thermally evaporated and patterned as gate electrode of metal-oxide-semiconductor (MOS) capacitors. No postmetal annealing was performed to avoid masking the defects created during the oxidation

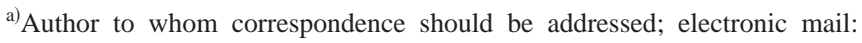
laip@eee.hku.hk
}

and/or nitridation. High-frequency (HF) capacitance-voltage $(C-V)$ measurement was carried out using HP4284A at room temperature under dark conditions. $\mathrm{SiO}_{2} / \mathrm{SiC}$ interface properties were studied by HF $C-V$ measurement after light illumination at deep depletion. The total deep interface states and fixed charges were estimated from a ledge feature occurring on HF $C-V$ curves and flatband shift. High-field stress $(\sim 7 \mathrm{MV} / \mathrm{cm})$, with the capacitor biased in accumulation, was used to study the device reliability.

The oxide thickness $t_{\mathrm{ox}}$, shown in Table $\mathrm{I}$, is calculated from the HF accumulation capacitance as oxide capacitance $C_{\text {ox }}$. It is seen that the 90 min nitridation adds a small thickness to the oxide grown during wet oxidation. The thickness is increased a bit further during subsequent annealing in wet $\mathrm{O}_{2}$ while negligible change for dry $\mathrm{O}_{2}$ annealing is due to lower growth rate in dry $\mathrm{O}_{2}$. The nitridation-induced oxide growth is much slower compared to the thickness of wet $\mathrm{O}_{2}$-grown oxide since an initial oxide already exists. The self-limiting growth kinetics can usually be explained by nitrogen incorporation into the oxide, which in turn blocks further oxidation of $\mathrm{SiC}$ substrates. This observation suggests a shorter time for nitridation at higher temperature so that more nitrogen can be incorporated before the thickness increases too much.

Figure 1 shows the HF $C-V$ curves of all the devices under dark conditions, swept from accumulation to depletion. All nitrided devices show improved flatband voltages relative to the OX device. The nitrided device annealed in dry/wet $\mathrm{O}_{2}$ shows smaller shift in flatband compared to the $\mathrm{N} 2 \mathrm{ON}$ device. The presence of significant interface traps causes such a stretch that the $C-V$ curve for the $\mathrm{N} 2 \mathrm{ON}$ device cannot reach the accumulation capacitance even at 5 $\mathrm{V}$. The flatband shift to the negative direction is mainly caused by real positive fixed charges. The flatband voltage $V_{\mathrm{fb}}$ is determined from the flatband capacitance $C_{\mathrm{fb}}$ as ${ }^{4}$

$$
\frac{C_{\mathrm{fb}}}{C_{\mathrm{ox}}}=\left(1+\frac{136 \sqrt{T / 300}}{t_{\mathrm{ox}} \sqrt{N_{D}}}\right)^{-1},
$$


TABLE I. Effects of nitridation and dry/wet $\mathrm{O}_{2}$ annealing on the oxide charge and interface-state density of MOS capacitor on $6 \mathrm{H}-\mathrm{SiC}$.

\begin{tabular}{lcccc}
\hline \hline \multicolumn{1}{c}{ Growth condition } & $\begin{array}{c}\text { Wet } \mathrm{O}_{2} \text { and } \\
\mathrm{N}_{2} \text { anneal }\end{array}$ & $\begin{array}{c}\text { Wet } \mathrm{O}_{2}, \mathrm{~N}_{2} \mathrm{O} \\
\text { nitridation and } \\
\mathrm{N}_{2} \text { anneal }\end{array}$ & $\begin{array}{c}\text { Wet } \mathrm{O}_{2}, \mathrm{~N}_{2} \mathrm{O} \\
\text { nitridation and } \\
\text { dry } \mathrm{O}_{2} \text { anneal }\end{array}$ & $\begin{array}{c}\text { Wet } \mathrm{O}_{2}, \mathrm{~N}_{2} \mathrm{O} \\
\text { nitridation and } \\
\text { wet } \mathrm{O}_{2} \text { anneal }\end{array}$ \\
\hline$t_{\mathrm{ox}}(\AA)$ & 393 & 407 & 406 & 410 \\
$C_{\mathrm{fb}} / C_{\mathrm{ox}}$ & 0.64 & 0.65 & 0.65 & 0.65 \\
$V_{\mathrm{fb}}(\mathrm{V})$ & -3.53 & 0.56 & -0.69 & -0.52 \\
$Q_{\mathrm{ox}}\left(\times 10^{12} \mathrm{~cm}^{-2}\right)$ & 2.66 & -0.49 & 0.74 & 0.51 \\
$D_{\mathrm{it}}\left(\times 10^{11} \mathrm{eV}^{-1} \mathrm{~cm}^{-2}\right)$ & 1.82 & 3.32 & 1.79 & 2.50 \\
\hline \hline
\end{tabular}

where $N_{D}$ and $T$ are the donor doping density and temperature $(\mathrm{K})$, respectively. The improved flatband shift for all the nitrided samples indicates reduction of positive fixed charge in the oxide during the $\mathrm{N}_{2} \mathrm{O}$ nitridation. The $C-V$ curves for $\mathrm{N} 2 \mathrm{OD}$ and $\mathrm{N} 2 \mathrm{OW}$ devices are closer to the ideal $C-V$ characteristics because reoxidation can improve the interface quality of nitrided devices. The oxide-charge density is estimated using the following relation:

$$
Q_{\mathrm{ox}}=-C_{\mathrm{ox}}\left(\frac{V_{\mathrm{fb}}-\phi_{\mathrm{ms}}}{q}\right),
$$

where $\phi_{\mathrm{ms}}$, the work function between aluminum and $6 \mathrm{H}-$ $\mathrm{SiC}$, is calculated to be $0.031 \mathrm{~V}$ for $n$-type $\mathrm{SiC}$. The value of $Q_{\text {ox }}$ of all the devices is indicated in Table I.

The shift in flatband voltage $\Delta V_{\mathrm{fb}}$ of all samples during high-field stress $(\sim 7 \mathrm{MV} / \mathrm{cm})$ is shown in Fig. 2. The positive $\Delta V_{\mathrm{fb}}$ for $\mathrm{N} 2 \mathrm{ON}$ indicates generation of acceptor-type interface states and negative oxide charge. A much smaller $\Delta V_{\mathrm{fb}}$ for the $\mathrm{N} 2 \mathrm{ON}$ device indicates significantly suppressed generation of interface states and oxide traps. From the maximum $\Delta V_{\mathrm{fb}}$ at $5000 \mathrm{~s}$ stress time, and increases of effec-

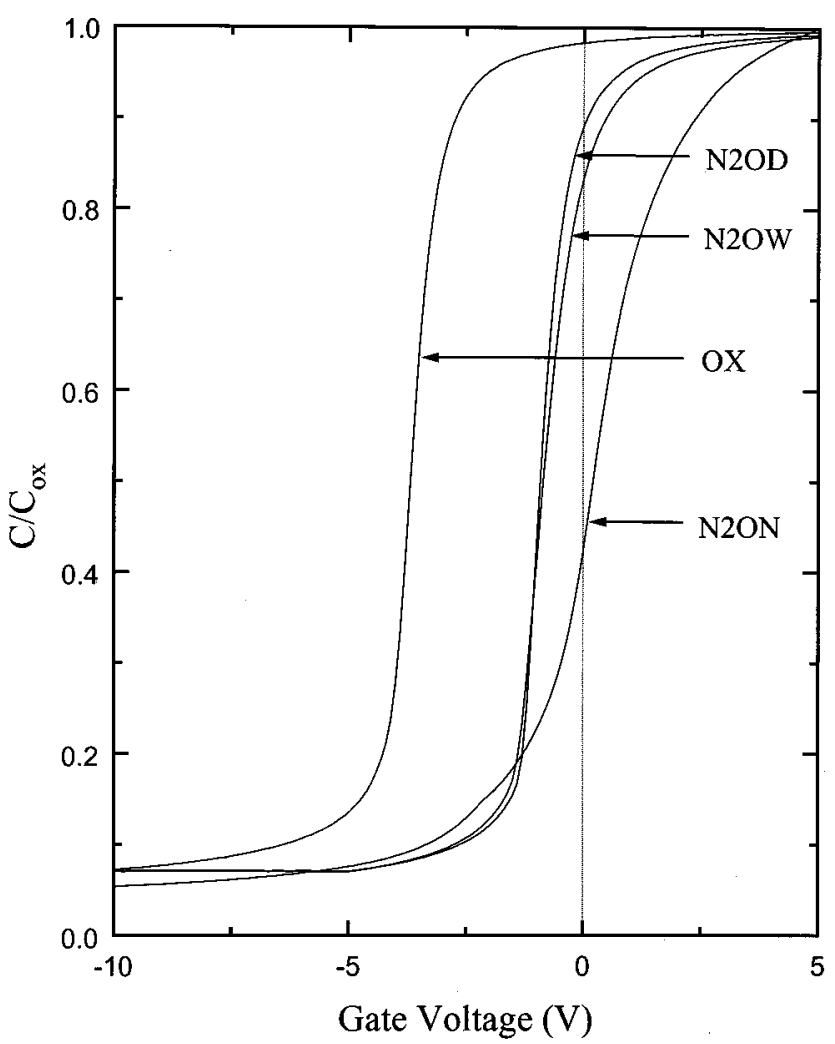

tive oxide charge, $Q_{\text {ox }}$ is estimated to be $4.0 \times 10^{11},-5.4$ $\times 10^{11}, 4.2 \times 10^{11}$, and $0.9 \times 10^{11} \mathrm{~cm}^{-2}$ for OX, N2ON, $\mathrm{N} 2 \mathrm{OD}$, and $\mathrm{N} 2 \mathrm{OW}$, respectively. The N2OD and N2OW devices exhibit slightly poorer reliability as compared to $\mathrm{N} 2 \mathrm{ON}$ because the dry/wet $\mathrm{O}_{2}$ annealing reduces the nitrogen content and hence strong $\mathrm{Si}-\mathrm{N}$ bonds in the oxide, and consequently reduces the robustness of the oxides.

The interface-state density $D_{\text {it }}$ estimated for all the devices is presented in Table I. An increase in $D_{\text {it }}$ for the $\mathrm{N}_{2} \mathrm{O}$-nitrided device means deteriorated interface quality of thermally grown oxide on the $n$-type $\mathrm{SiC}$ substrate due to the fact that nitridation roughens the interface. ${ }^{3}$ The interface quality is found to recover after dry/wet $\mathrm{O}_{2}$ annealing for $\mathrm{N} 2 \mathrm{OD}$ and $\mathrm{N} 2 \mathrm{OW}$ devices because reoxidation can partially repair the damaged interface.

In conclusion, results are presented on the effects of dry and wet $\mathrm{O}_{2}$ annealings on the interface properties of nitrided oxides on $n$-type $\mathrm{SiC}$. The results show that nitridation deteriorates the interface quality, while subsequent $\mathrm{O}_{2}$ annealing (especially in dry $\mathrm{O}_{2}$ ) can repair the interface. The reliability of the $\mathrm{O}_{2}$-annealed nitrided oxides is slightly reduced due to

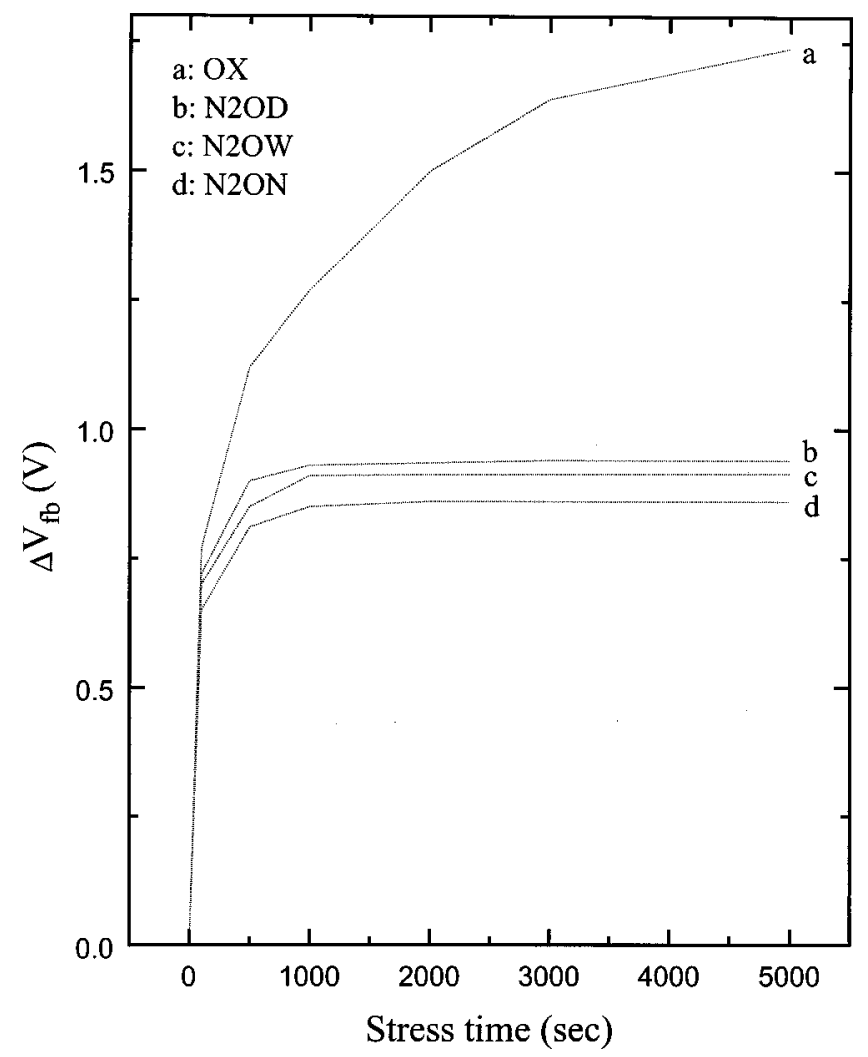


a decrease of nitrogen content during annealing. Therefore, an optimal condition is required for $\mathrm{O}_{2}$ annealing to provide a good compromise between interface quality and reliability.

This work is financially supported by RGC, Hong Kong. The contribution of Dr. J. P. Xu is also gratefully acknowledged.
${ }^{1}$ D. Alok, P. K. Mclarty, and B. J. Baliga, Appl. Phys. Lett. 65, 2177 (1994).

${ }^{2}$ S. T. Sheppard, J. A. Cooper, Jr., and M. R. Melloch, J. Appl. Phys. 75, 3205 (1994)

${ }^{3}$ S. Dimitrijev, H. F. Li, H. Barry Harrison, and D. Sweatman, IEEE Electron Device Lett. 18, 175 (1997).

${ }^{4}$ D. K. Schroder, in Semiconductor Material and Device Characterization, 2nd ed. (Wiley, New York, 1998). 